\title{
PROPOSAL OF A HYSTERESIS CONTROLLER WITH CONSTANT SWITCHING FREQUENCY
}

\author{
Marcos T. Galelli, Fernando L. Tofoli, Márcio S. Vilela, Ernane A. A. Coelho, \\ João Batista Vieira Jr., Luiz Carlos de Freitas, Valdeir J. Farias \\ Universidade Federal de Uberlândia \\ Faculdade de Engenharia Elétrica \\ Núcleo de Eletrônica de Potência \\ Av. João Naves de Ávila, 2160, Campus Santa Mônica, Bloco "3N" \\ CEP 38400-902, Uberlândia, MG, Brasil, +55-34-32394166 \\ E-mail: batista@ufu.br
}

\begin{abstract}
This paper introduces a new control technique for power factor correction in ac-dc converters. It has the advantages of conventional hysteresis control strategy and the prominent characteristics PWM control, since the limits of the hysteresis band can be adjusted to provide fixed switching frequency. The operating principles, theoretical analysis and results regarding a single-phase boost converter are presented to validate the proposal.
\end{abstract}

Keywords - hysteresis control, low harmonic distortion, power factor correction.

\section{INTRODUCTION}

The growing number of nonlinear loads such as diode or thyristor rectifiers, switch-mode power supplies and adjustable speed drives generates harmonic currents causing various problems to other equipment connected to the point of common coupling. Typical problems are overheated machines, transformers and power cables, current flow through the neutral conductor, flicker effects, and malfunctioning of sensitive devices. The reduction of the harmonic content and also high power factor are desirable aspects in ac-dc converters, because they are potential harmonic sources and may affect power quality [1].

Throughout the years, two switching techniques have become popular: PWM and hysteresis modulation [2]. The hysteresis control introduces a minor error in the average input current and provides better dynamic response than the PWM control, but an inherent drawback is the variable switching frequency. Therefore the control circuit is supposed to be designed for a large band, otherwise low frequency harmonics will result [3] [4].

Hysteresis control is essentially an analogic technique. Despite the advantages given by the digital controls, in terms of interfacing, maintenance, flexibility, and integration, their accuracy and response speed are often inadequate for current control in highly demanding applications, such as active filters and high-precision drives [5]-[7]. Indeed, in these applications, current reference waveforms characterized by high harmonic content and fast transient response must be followed by good accuracy. In these cases, the hysteresis method can be a good solution, provided some improvements

Manuscript submitted on December 10, 2004. First review, April 14, 2005. Second review, May 31, 2005. Recommended by Special Editors Marcelo G. Simões and Humberto Pinheiro. are introduced to overcome its main limitations, which are the variations of the switching frequency and the sensitivity to phase commutation interferences. To this purpose, a variety of alternatives, both analog and digital, have been proposed by several authors [8]-[15].

However, when high switching frequency is demanded, analog solutions offer the fastest performance with a relatively simple implementation. A fully analog technique, which eliminates the interference and gives constant switching frequency, was presented in [8]. This technique was extensively used and proved to be robust and reliable.

This paper introduces a novel control technique that controls the input current, allowing ac-dc converters to operate with constant switching frequency with the advantages of conventional hysteresis and PWM controllers. The control system can be implemented using analog circuits, and the proposal is discussed as follows.

\section{HYSTERESIS CONTROLLER WITH CONSTANT SWITCHING FREQUENCY}

\section{A. Theoretical Background}

The basic principle of the proposed technique consists in determining the ideal time interval between the switching instant and the crossing instant of the reference and input currents. The input current is then supposed to oscillate around the reference current with fixed frequency.

Fig. 1. shows the behavior of the input current in an incremental time interval, where the reference current is almost constant, since the switching frequency is much greater than the line frequency.

This control strategy can be applied to most of the singlephase ac-dc converters, without any essential change in the original topology [16]. Furthermore, the study is also extended to a three-phase boost converter in [16]. However, the analysis carried out here considers a conventional singlephase boost converter operating in continuous conduction mode due to simplicity, because it has only two operating stages.

In order to analyze the proposed control strategy, the circuit shown in Fig. 2 must be considered, where it can be seen that the converter operation can be defined in two stages. Voltage $V_{x}$ in the first and second stages is defined as $V_{x 1}$ and $V_{x 2}$, respectively, but such values depend on the converter in question. For instance, if the converter is a fullbridge topology, voltages $V_{x 1}$ and $V_{x 2}$ will be $+V_{o}$ and $-V_{o}$, respectively [16]. For a boost converter, voltages $V_{x 1}$ and $V_{x 2}$, will be $+V_{o}$ and null, respectively. 


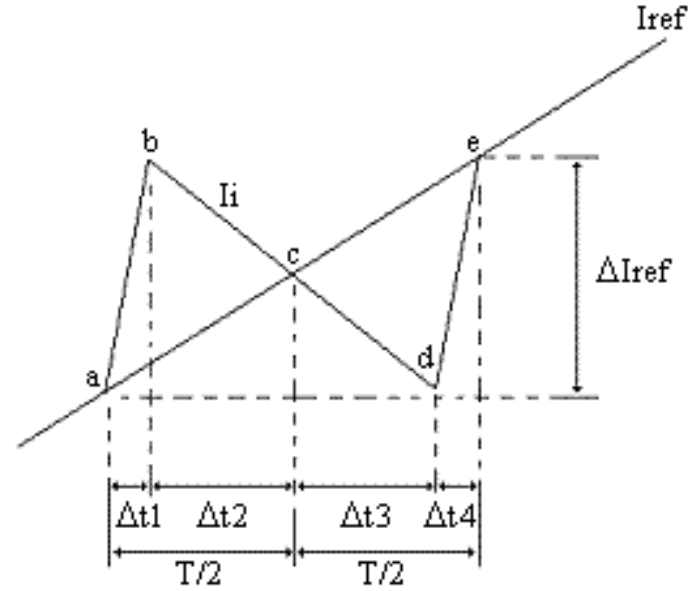

Fig. 1. Input current profile within a switching period.

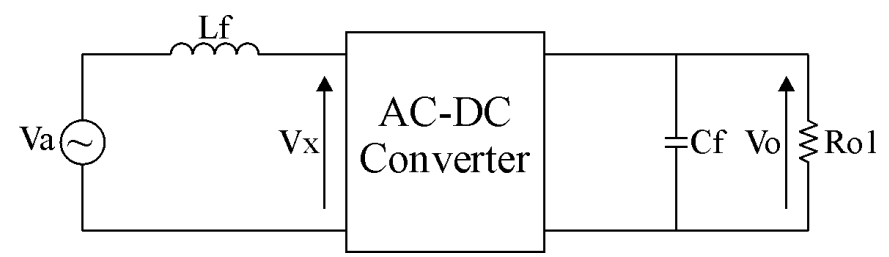

Fig. 2. Generic power converter with two operating stages.

However, independently of the topology, voltage $V_{x I}$ will always be greater than the input voltage, and voltage $V_{x 2}$ is less than the input voltage or null. Additionally, if the switching frequency is considered much greater than the line frequency, the behavior of the current through the filter inductor can be described according to Fig. 1, which corresponds to an ideal situation i.e. triangles $a b c$ and $c d e$ have the same area. In order to maintain this condition, it is necessary to determine $\Delta t_{1}$ and $\Delta t_{3}$, which correspond to the time intervals during which the switch is turned on and off, respectively. Such intervals are determined as a function of the circuit parameters, in order to assure constant switching frequency.

Expressions (1) and (2) represent the increasing and decreasing rates of the input current, respectively.

$$
\begin{aligned}
& -V_{x 2}+V_{a}=L_{f} \cdot \frac{d I_{i}}{d t} \\
& -V_{x 1}+V_{a}=L_{f} \cdot \frac{d I_{i}}{d t}
\end{aligned}
$$

If the switching frequency is considered much greater than the frequency of the reference current, output voltage and $\left(d I_{\text {ref }} d t\right)$ ratio are constant. In addition to this, the increasing and decreasing rates of the current through the filter inductor are constant. Therefore triangles $a b c$ and $c d e$ have the same area and the following expressions are valid.

$$
\begin{aligned}
& \Delta t_{2} \cong \Delta t_{3} \\
& \Delta t_{1} \cong \Delta t_{4}
\end{aligned}
$$

$\Delta t_{1}$ - time interval during which the current derivative is positive, from the crossing point with the reference current to the instant of commutation;

$\Delta t_{2}$ - time interval during which the current derivative is negative, from the instant of commutation to the crossing point with the reference current;

$\Delta t_{3}$ - time interval during which the current derivative is negative, from the crossing point with the reference current to the instant of commutation;

$\Delta t_{4}$ - time interval during which the current derivative is positive, from the instant of commutation to the crossing point with the reference current.

Analyzing Fig. 1, expressions (5) and (6) result.

$$
\begin{gathered}
\Delta t_{1}+\Delta t_{2}=T / 2 \\
\int_{t}^{t+\Delta t_{1}} \frac{\left(-V_{x 2}+V_{a}\right) \cdot d t}{L_{f}}+\int_{t+\Delta t_{1}}^{t+T / 2} \frac{\left(-V_{x 1}+V_{a}\right) \cdot d t}{L_{f}}=\frac{\Delta I_{r e f}}{2}
\end{gathered}
$$

where $\Delta I_{\text {ref }}$ is the reference current variation, and $T$ is the switching period. Assuming $\left(d I_{\text {ref }} / d t\right)$ constant in the switching period, $\Delta I_{r e f}$ can be given as:

$$
\Delta I_{r e f}=T \cdot \frac{d I_{r e f}}{d t}
$$

Finally, from expressions (5) to (7), interval $\Delta t_{l}$ is obtained.

$$
\Delta t_{1}=\frac{T}{2 \cdot\left(V_{x 1}-V_{x 2}\right)} \cdot\left(V_{x 1}-\frac{2}{T} \int_{t}^{t+T / 2} V_{a} \cdot d t+L_{f} \cdot \frac{d I_{r e f}}{d t}\right)
$$

If the same procedure is followed, interval $\Delta t_{2}$ can also be calculated.

$$
\Delta t_{2}=\frac{T}{2 \cdot\left(V_{x 1}-V_{x 2}\right)}\left(-V_{x 2}+\frac{2}{T} \int_{t}^{t+T / 2} V_{a} \cdot d t-L_{f} \cdot \frac{d I_{r e f}}{d t}\right)
$$

From time intervals $\Delta t_{l}$ and $\Delta t_{2}$, it is possible to define the upper and lower limits of the hysteresis band, which according to Fig. 3 must be symmetrical to the reference current so that constant switching frequency is achieved.

$$
\begin{gathered}
I_{\text {ref (up) }}=\frac{1}{L_{f}} \cdot \int_{0}^{\Delta t_{1}}\left(-V_{x 2}+V_{a}-L_{f} \cdot \frac{d I_{r e f}}{d t}\right) \cdot d t+I_{r e f} \\
I_{\text {ref (low) }}=\frac{1}{L_{f}} \cdot \int_{0}^{\Delta t_{2}}\left(V_{x 1}-V_{a}+L_{f} \cdot \frac{d I_{r e f}}{d t}\right) \cdot d t+I_{r e f}
\end{gathered}
$$

\section{B. Definition of The Hysteresis Band Considering A Boost Converter}

The operation of a conventional single-phase boost converter can be defined in two stages. When switch $S$ is turned off, the voltage across the filter inductor is $\left(V_{a}-V_{o}\right)$, otherwise it is $V_{a}$.

In this case, voltages $V_{x l}$ and $V_{x 2}$ are $+V_{o}$ and null, respectively. Equations (8) and (9) can be simplified as follows:

$$
\begin{gathered}
\Delta t_{1}=\frac{T}{2 \cdot V_{o}} \cdot\left(V_{o}-V_{a}+L_{f} \cdot \frac{d I_{r e f}}{d t}\right) \\
\Delta t_{2}=\frac{T}{2 \cdot V_{o}} \cdot\left(V_{a}-L_{f} \cdot \frac{d I_{r e f}}{d t}\right)
\end{gathered}
$$




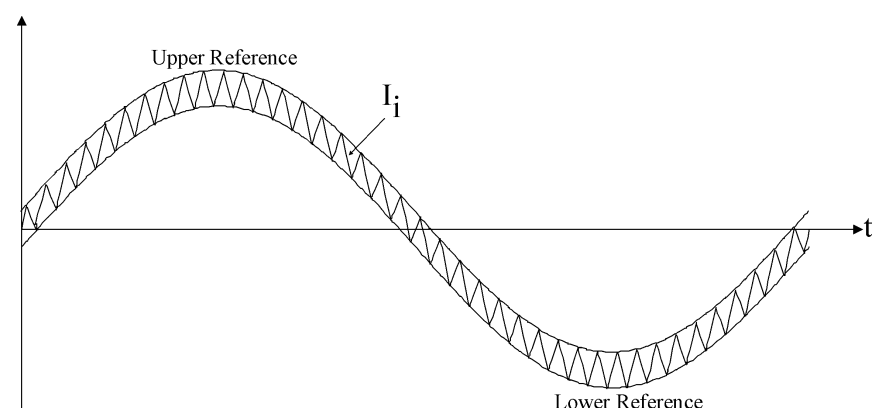

Fig. 3. Hysteresis band.

It can be demonstrated that a maximum relative error due to the conditions given in (3) to (5) results, as follows:

$$
\begin{gathered}
\operatorname{Error}\left(\Delta t_{1}\right)=\frac{\omega \cdot T \cdot V_{a} \cdot \cos (\omega t)}{2 \cdot\left(V_{o}-\int_{t}^{t+T / 2}\left|V_{a}\right| \cdot d t+L_{f} \cdot \frac{d I_{r e f}}{d t}\right)} \\
\operatorname{Error}\left(\Delta t_{2}\right)=\frac{\omega \cdot T \cdot V_{a} \cdot \cos (\omega t)}{2 \cdot\left(\int_{t}^{t+T / 2}\left|V_{a}\right| \cdot d t-L_{f} \cdot \frac{d I_{r e f}}{d t}\right)}
\end{gathered}
$$

where $\omega$ is the line frequency. Since $\Delta t_{1}$ and $\Delta t_{2}$, represent the increasing and decreasing rates of the input current in Fig. 3, respectively, the relative error is consequently related to the switching frequency variation.

From (12) and (13), it is possible to define the upper and lower limits of the hysteresis band as (16) and (17), respectively. According to Fig. 3, they must be symmetrical to the reference current so that constant switching frequency is achieved.

$$
\begin{aligned}
& I_{r e f(u p)}=I_{r e f}+\frac{T}{2 \cdot V_{o} \cdot L_{f}} \cdot\left(V_{o}-V_{a}+L_{f} \cdot \frac{d I_{r e f}}{d t}\right) \\
& \cdot\left(V_{a}-L_{f} \cdot \frac{d I_{r e f}}{d t}\right) \\
& I_{r e f(l o w)}=I_{r e f}-\frac{T}{2 \cdot V_{o} \cdot L_{f}} \cdot\left(V_{o}-V_{a}+L_{f} \cdot \frac{d I_{r e f}}{d t}\right) \\
& \cdot\left(V_{a}-L_{f} \cdot \frac{d I_{r e f}}{d t}\right)
\end{aligned}
$$

\section{Implementation of The Controller}

Fig. 4 shows the simplified diagram representing the controller applied to a boost converter. Some aspects must be considered about the implementation of the analogic circuit.

When the input voltage becomes null, and the reference current starts increasing, the increasing rate of the current through the filter inductor is not enough to follow the reference current, until $V_{a} / L_{f}$ ratio becomes greater than $\left(d I_{\text {ref }} d t\right)$. This can be explained because the increasing rate of $I_{i}$ depends only on the input voltage. Additionally, this will cause the switching frequency to be reduced at this point, since switch $S$ remains turned on, until the input current equals the reference current.

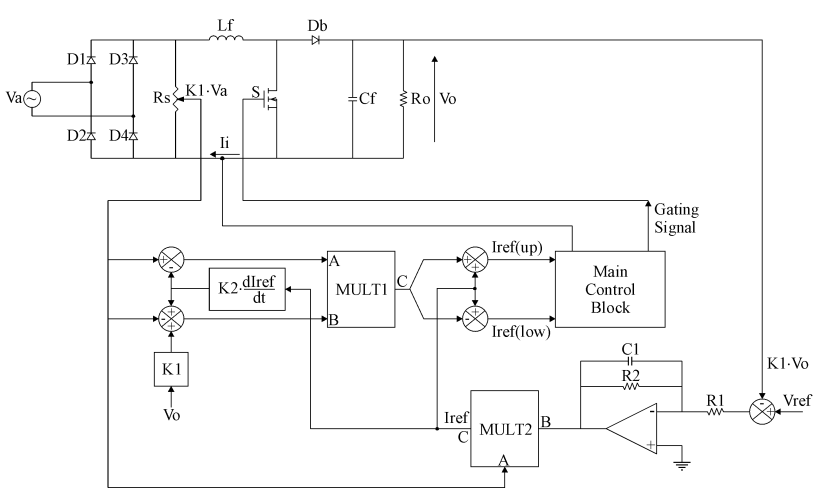

Fig. 4. Proposed controller associated with a boost converter.

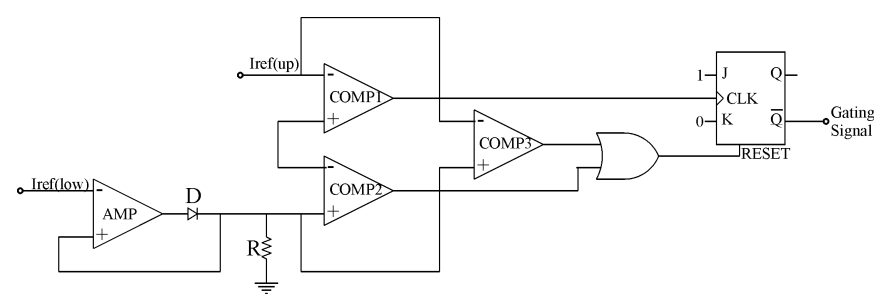

Fig. 5. Representation of the main control block.

Since the current through the filter inductor can not flow in the reverse direction, the lower limit of the hysteresis band is always supposed to be a positive value. If $I_{\text {ref }(u p)}$ becomes less than $I_{\text {refflow), }}$, switch $S$ must remain turned on.

Reference signals are obtained using sum and multiplier circuits. Parameter $K_{2}$ is proportional to inductor $L_{f}$ and constant $K_{1}$, and it must be defined in order to keep voltages $V_{\Delta t 1}$ and $V_{\Delta t 2}$ within the band limits. The switching frequency is set by constant $K_{I}(18)$, which is squared by the multiplier circuit.

$$
K_{1}=\sqrt{\frac{T}{2 \cdot L_{f} \cdot V_{o}}}
$$

Fig. 5 shows the discrete representation of the main control block, whose operating principle is quite simple. When the input current is less than the reference current, comparator COMP1 drives the CLK input of the JK flip-flop, setting the output to high. When the input current reaches the upper limit of the band, comparator COMP2 drives the $R E S E T$ input of the $J K$ flip-flop again, consequently setting the output to low.

\section{SIMULATION RESULTS}

Simulation tests were performed on a boost converter to demonstrate the controller performance. Conventional hysteresis control was also implemented to establish an eventual comparison with the proposed technique. The average switching frequency is the same in both cases, as the parameters set in Table I is employed.

Fig. 6 and Fig. 7 show results concerning the conventional hysteresis controller and the proposed one, respectively. Fig. 6 (a) and Fig. 7 present the input current waveform. Fig. 6 (b) and Fig. 7 (b) correspond to the frequency spectrum of the input current, where switching frequency variation is evidenced. In Fig. 6 (c) and Fig. 7 (c), one can see that such variation is much greater for the conventional hysteresis controller. 


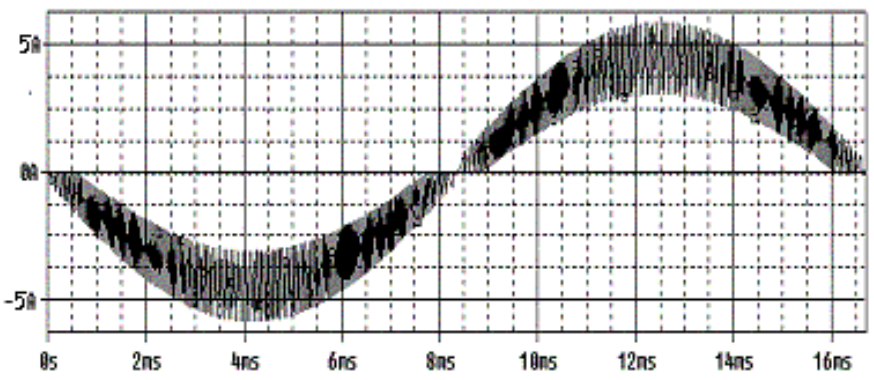

(a) Input current

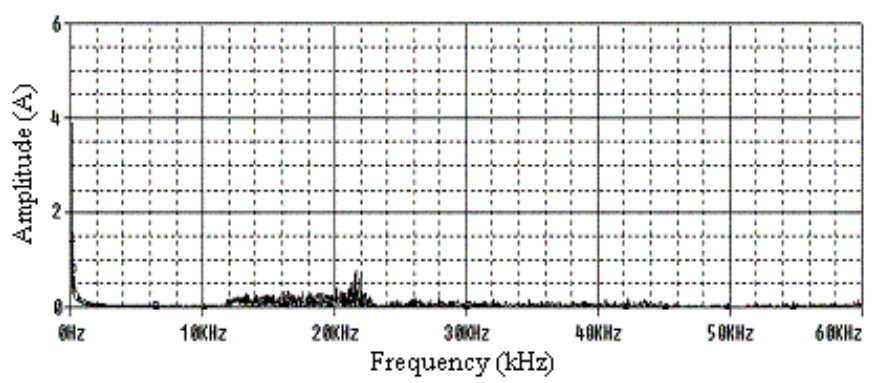

(b) Frequency spectrum of the input current

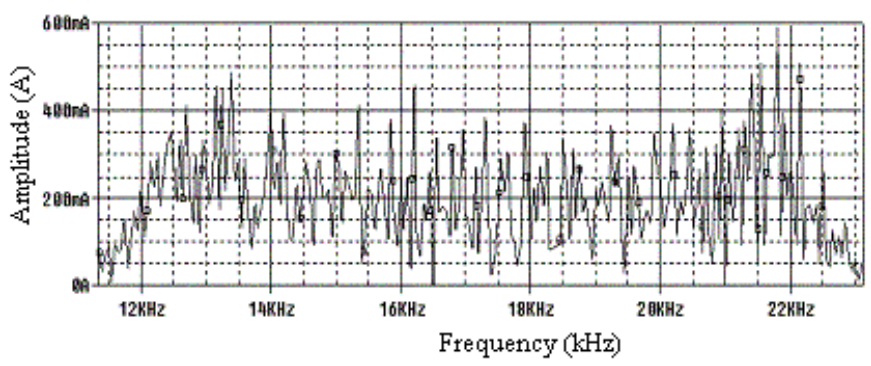

(c) Detailed view indicating the switching frequency variation

Fig. 6. Simulation results obtained with the conventional hysteresis controller.

Table I

Parameters set used in the tests

\begin{tabular}{l|l}
\hline \multicolumn{1}{c}{ Parameter } & \multicolumn{1}{c}{ Value } \\
\hline Input voltage & $V_{i}=127 \mathrm{Vrms}$ \\
\hline Output voltage & $V_{o}=250 \mathrm{Vdc}$ \\
\hline Filter inductor & $L_{f}=2.1 \mathrm{mH}$ \\
\hline Filter capacitor & $C_{f}=1000 \mu \mathrm{F}$ \\
\hline Load current & $I_{o}=2 \mathrm{~A}$ \\
\hline Output Power & $P_{o}=500 \mathrm{~W}$ \\
\hline Average switching frequency & $f_{s}=20 \mathrm{kHz}$ \\
\hline Switch $S$ & IRFP264 \\
\hline Boost diode $D_{b}$ & MUR860 \\
\hline
\end{tabular}

Additionally, the current $T H D$ considering the harmonic content to the fiftieth order is $3.7 \%$ for the conventional controller, and $1.5 \%$ for the proposed one.

\section{EXPERIMENTAL RESULTS}

In order to validate the theoretical assumptions, and also the results in Section III, an experimental prototype of the boost converter associated with the proposed controller was implemented. Results are presented and discussed as follows.

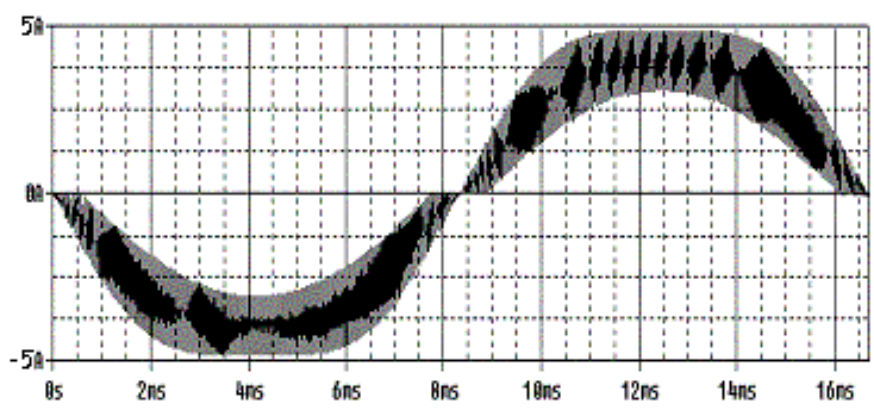

(a) Input current

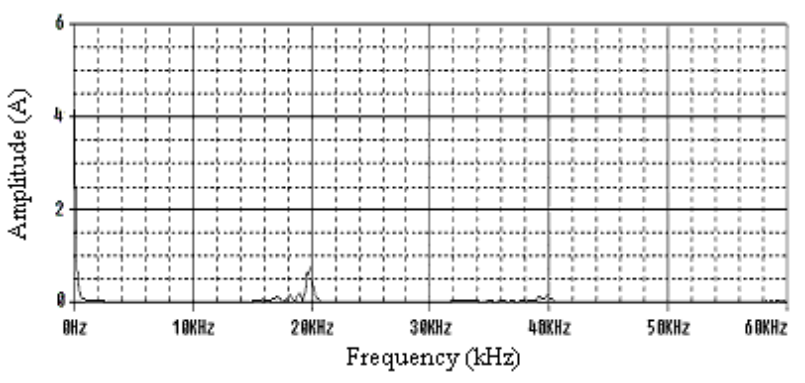

(b) Frequency spectrum of the input current

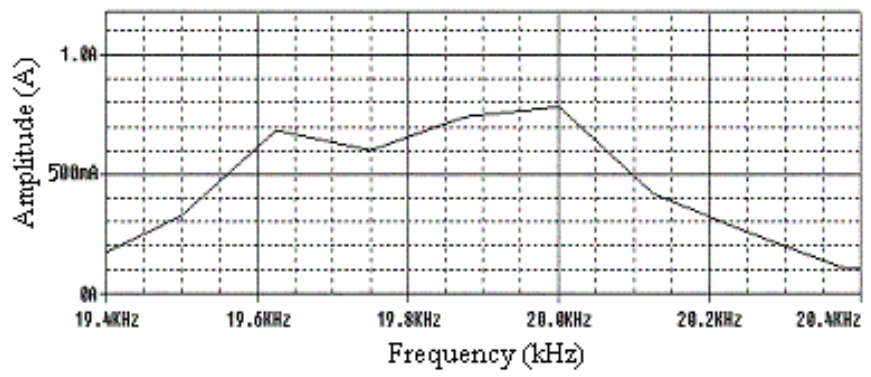

(c) Detailed view indicating the switching frequency variation

Fig. 7. Simulation results obtained with the proposed hysteresis controller.

Fig. 8 shows the rectified input current obtained from a current sensor. This waveform represents the hysteresis band itself.

Fig. 9 corresponds to the input voltage and input current waveforms, where power factor correction is evidenced.

Fig. 10 (a) and (b) represent the harmonic content of the input voltage and input current, respectively, as voltage $T H D$ is $2.45 \%$ and current $T H D$ is $5.74 \%$.

Finally, Fig. 11 shows the frequency spectrum of the input current, where the switching frequency variation can be seen.

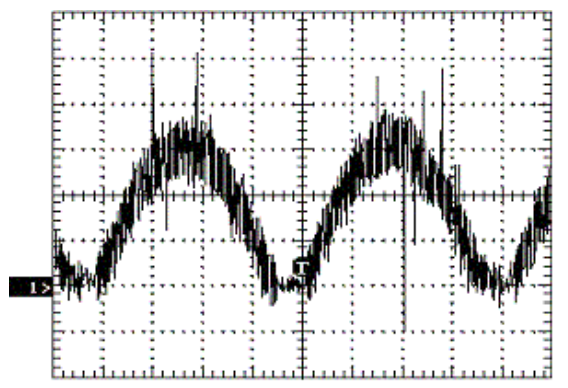

Fig. 8. Rectified input current.

Scales: $I_{i}-200 \mathrm{~mA} / \mathrm{div}$; time $-2 \mathrm{~ms} / \mathrm{div}$. 


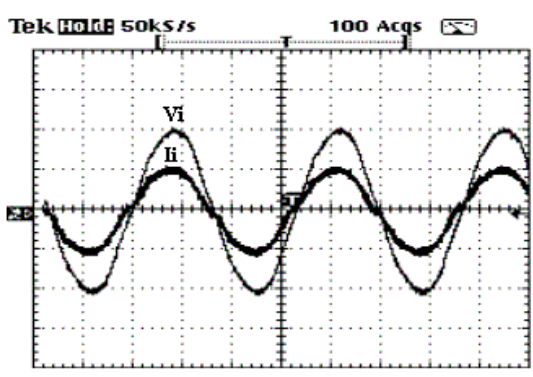

Fig. 9. Input voltage and input current. Scales: $V_{i}-100 \mathrm{~V} / \mathrm{div}$; $I_{i}-5 \mathrm{~A} / \mathrm{div} . ;$ time $-5 \mathrm{~ms} / \mathrm{div}$.

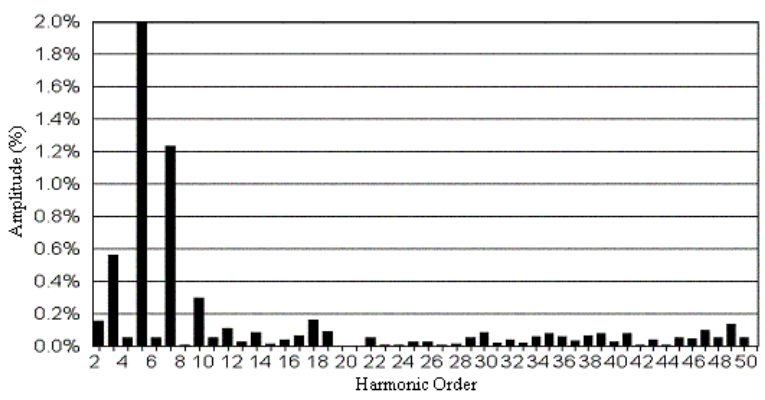

(a) Input voltage

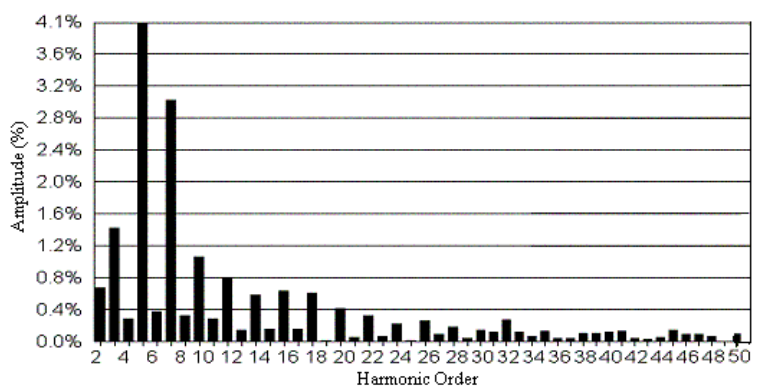

(b) Input current

Fig. 10. Harmonic content.

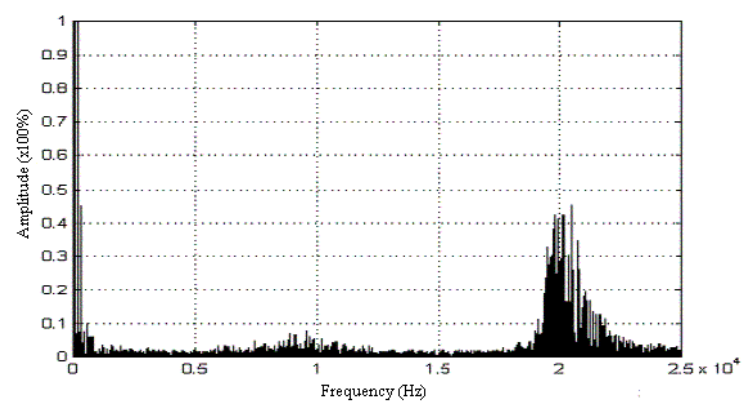

(a) Frequency spectrum

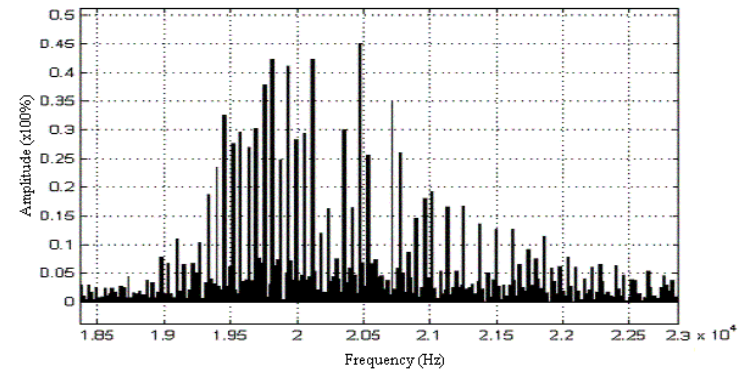

(b) Detailed view indicating the switching frequency variation

\section{CONCLUSION}

This paper has presented a novel control technique that has the advantages of conventional hysteresis and PWM control techniques. If the upper and lower limits of the hysteresis band are modified, constant switching frequency can be achieved.

As it can be seen in the tests, the switching frequency variation is reduced, as expected in the mathematical study. It is also possible to say that the relative error decreases when the average switching frequency increases, as it may become negligible.

\section{ACKNOWLEDGEMENT}

The authors gratefully acknowledge CAPES and CNPq for the financial support to this work, and also Texas Instruments and $\mathrm{ON}$ Semiconductor for sending free samples.

\section{REFERENCES}

[1] A.F. Souza, I. Barbi, "Retificadores de Alto Fator de Potência com Comutação Suave e Baixa Perda de Condução", pp. 01-10, Revista SOBRAEP, Julho de 1996, vol. 1.

[2] H. Kanaan, K. Al-Haddad, R. Chaffai, L. Duguay, F. Fnaiech "A Comparative Study of Hysteresis and PWM Control Techniques Applied to An Injection-CurrentBased Three-Phase Rectifier", Canadian Conference on Electrical and Computer Engineering, 2001, vol. 2, pp. 785-792.

[3] O. Stihi, B.T. Ooi, "A Single-Phase Controlled-Current PWM Rectifier," IEEE Transactions on Power Electronics, 2000, vol. 3, no. 4, pp. 453-459.

[4] P.N. Enjeti, R. Martinez, "A High Performance Single Phase AC to DC Rectifier with Input Power Factor Correction", IEEE APEC'93 Conference Proceeding, 1993, pp. 190-195.

[5] A. Kawamura, K. Ishihara, "High Frequency Deadbeat Control of Three Phase PWM Inverter Used for Uninterruptible Power Supply", in Conf. Rec. IEEE PESC'88, 1988, pp. 644-649.

[6] M. Marchesoni, "High Performance Current Control Techniques for Applications to Multilevel High Power Voltage Source Inverters", in Conf. Rec. IEEE PESC'89, Milwaukee, WI, June 1989, pp. 672-682.

[7] T.G. Habetler, "A Space Vector Based Rectifier Regulator for AC/DC/AC Converters", in Proc. EPE'91 European Conference on Power Electronics and Applications, Florence, Italy, Sept. 1991, pp. 2.1012.107.

[8] L. Malesani, P. Tenti, “A Novel Hysteresis Control Method For Current Controlled VSI PWM Inverters with Constant Modulation Frequency", IEEE Transactions on Industry Applications, vol. 26, Jan./Feb. 1990, pp. 88-92.

[9] A.V. Anunciada, M.M. Silva, "A New Current Mode Control Process and Applications," in Conf. Rec. IEEE PESC'89, 1989, pp. 683-694.

Fig. 11. Frequency spectrum of the input current. 
[10] J.A. Dente, J. Esteves, "Improved Hysteresis Controlled Inverter for A Three Phase Brushless Servo Motor", in Conf. Rec. EPE'89, Aachen, Germany, Oct. 1989, pp. 257-260.

[11]B.K. Bose, "An Adaptive Hysteresis-Band Current Control Technique of A Voltage-Fed PWM Inverter For Machine Drive System," IEEE Transactions on Industrial Electronics, vol. 37, Oct. 1990, pp. 402-408.

[12] L. Malesani, P. Tenti, E. Gaio, R. Piovan, "Improved Current Control Technique of VSI PWM Inverters with Constant Modulation Frequency and Extended Voltage Range," ", IEEE Transactions on Industry Applications, vol. 27, Mar./Apr. 1991, pp. 365-369.

[13] K. Tungpimolrut, M. Matsui, T. Fukao, “A Simple Limit Cycle Suppression Scheme for Hysteresis Current Controlled PWM-VSI with Consideration of Switching Delay Time," in Conf. Rec. IEEE/IAS 1992 Annual Meeting, Houston, TX, Oct. 1992, pp. 1034-1041.

[14] Q. Yao, D.G. Holmes, "A Simple, Novel Method for Variable Hysteresis-Band Current Control of a Three Phase Inverter with Constant Switching Frequency," in Conf. Rec. IEEE IAS'93, Toronto, Ont., Canada, Oct. 1993, pp. 1122-1129.

[15]P.S. Ninkovic, “A Novel Constant-Frequency Hysteresis Current Control of PFC Converters", Proceedings of the 2002 IEEE International Symposium on Industrial Electronics, 2002. ISIE 2002, vol. 4, July 2002, pp. 1059-1064.

[16] M.S. Vilela, "Proposta de Uma Técnica de Controle para Correção do Fator de Potência de Entrada dos Conversores CA/CC", Uberlândia, Minas Gerais, Brasil, 2002. Tese de Doutorado - UFU.

\section{BIOGRAPHIES}

Marcos Tadeu Galelli was born in Uberaba, Minas Gerais, Brazil, on December $28^{\text {th }}, 1977$. He received the BSc and MSc degrees in Electrical Engineering from the Federal University of Uberlândia, Brazil, in 2003 and 2005, respectively. He is currently with the National Service for Industrial Apprenticeship as an assistant professor and engineer. His research interest include microcontrollers, robotics and control strategies applied to power converters.

Fernando Lessa Tofoli was born on March $11^{\text {th }}, 1976$, in São Paulo, São Paulo, Brazil. He received the BSc and MSc degrees in Electrical Engineering from the Federal University of Uberlândia, Brazil, in 1999 and 2002, respectively. Nowadays he is $\mathrm{PhD}$ student at the Power Electronics Research Group of the same university. His research interests include power quality related issues, high power factor rectifiers and soft switching techniques applied to static power converters.

Márcio da Silva Vilela was born in Jiparaná, Rondônia,
Brazil. He received the $\mathrm{BSc}, \mathrm{MSc}$ and $\mathrm{PhD}$ degrees in Electrical Engineering from the Federal University of Uberlândia, Brazil, in 1993, 1996 and 2004, respectively. He is currently with the Foundation for Superior Teaching of Rio Verde. His research interests are control techniques applied to static power converters, microcontrollers and high power factor rectifiers.

Ernane Antônio Alves Coelho was born in Teófilo Otoni, Minas Gerais, Brazil, on April $1^{\text {st }}, 1962$. He received the BSc degree in Electrical Engineering from the Federal University of Minas Gerais, Brazil, in 1987 and the MSc and $\mathrm{PhD}$ degrees in Electrical Engineering from the Federal University of Santa Catarina, Florianópolis, Brazil, in 1989, and from the Federal University of Minas Gerais, in 2000, respectively. Presently he is titular professor of the Department of Electrical Engineering of the Federal University of Uberlândia, Brazil. His research interests are PWM inverters, power factor correction circuits and new topologies using digital control.

João Batista Vieira Jr. was born in Panamá, Goiás, Brazil, on March $23^{\text {rd }}, 1955$. He received the BSc degree in Electrical Engineering from the Federal University of Uberlândia, Brazil, in 1980 and the MSc and PhD degrees from the Federal University of Santa Catarina, Brazil, in 1984 and 1991, respectively. He started working as instructor teacher at the Department of Electrical Engineering of the Federal University of Uberlândia in 1980 where he is currently titular professor. His research interests include high-frequency power conversion, modeling and control of converters, power factor correction circuits and new converters topologies. He is member of the Brazilian Society of Automation (SBA) and member of the Brazilian Society of Power Electronics (SOBRAEP).

Luiz Carlos de Freitas was born in Prata, Minas Gerais, Brazil, on April $1^{\text {st }}, 1952$. He received the BSc degree in Electrical Engineering from the Federal University of Uberlândia, Brazil, in 1975, and the MSc and PhD degrees from the Federal University of Santa Catarina, Brazil, in 1985 and 1992, respectively. Nowadays he is with Department of Electrical Engineering of the Federal University of Uberlândia, Brazil. His research interests include high-frequency power conversion, modeling and control of converters, power factor correction circuits and novel converters topologies.

Valdeir José Farias was born in Araguari, Minas Gerais, Brazil, on November $18^{\text {th }}, 1947$. He received the BSc, MSc and $\mathrm{PhD}$ degrees in Electrical Engineering from the Federal University of Uberlândia, Brazil, in 1975, Federal University of Minas Gerais, Brazil, in 1981, and State University of Campinas, Brazil, in 1989, respectively. Nowadays he is with the Department of Electrical Engineering of the Federal University of Uberlândia, Brazil. His research interests are soft switching converters and active power filters. 